\title{
Where We Grow up does Really Matter: Best Practices for Child-Friendly Cities Applied in Tarlabasi (Istanbul)
}

\author{
Burcin Mizrak ${ }^{1, *}$, Sergio Mattia ${ }^{2}$, Alessandra Pandolfi ${ }^{2}$ \\ ${ }^{1}$ Yıldız Technical University, 34349 Besiktas, Istanbul, Turkey \\ ${ }^{2}$ Department of Architecture and Urban Studies, Polytechnic of Milan, 20133 Milano, Italy \\ *Corresponding Author: mizrakburcin@yahoo.com
}

Copyright (C) 2014 Horizon Research Publishing All rights reserved.

\begin{abstract}
The article innovative aim is to introduce a research made to suggest some simple ways to improve the planning and design strategies for ensuring the highest sustainability level in child-friendly cities. The environments surrounding us strongly affect our perception of belonging to a place, and our social, mental, physical health. Therefore, designing and planning friendly environments for people of all ages should be perceived as one of the most important responsibilities for planners and politicians. At this point, in order to make cities friendlier for its inhabitants, it is considered useful to focus on the most vulnerable classes of people living in urban environments, such as children, because a city that is friendly for its kids will be welcoming also for anyone else. As a matter of facts, a child-friendly city is usually a urban environment that is suitable for most of its inhabitants and this is even more important in the most critical situations, such as the poorest slums of a developing city, like Istanbul, and its most fragile neighborhoods, like Tarlabasi. The research results highlighted that Tarlabasi has unique spatial child-friendly characteristics, despite its physical, social, and economic disadvantages, and these conditions can be dramatically improved with some very simple and affordable projects.
\end{abstract}

Keywords Child Friendly Cities, Children Environments, Participation of Children in the Planning Process, Integration, Accessibility, Childhood Spaces, Tarlabasi - Istanbul (Turkey)

\section{Introduction}

«Wir bauen eine neue Stadt, die soll die allerschönste sein, die soll die allerschönste sein»

«Let's build a new city, it will be the most beautiful one, it will be the most beautiful one»

Paul Seitz \& Paul Hindemith, "Wir bauen eine Stadt"
(1930)

The child-friendliness of environments is a multifaceted topic defined by broad criteria that have been approached and evaluated several times in the last decades, even if the practical use of these principles resulted to be significantly hard for the extensive methodology, described in the sector literature, and the wide character of the matter, that usually involve expensive measures to reach minimal effects. As Broberg et al. [1] suggests, due to the broadness of the topic, the definitions of the friendliness criteria «have produced surprisingly few attempts to evaluate how child-friendly various types of physical environments are», in order to understand «how the structure of the built environment contributes to environmental child friendliness». This is why the innovation in the research here presented is aimed at proving that some significant results can be reached even through simple and inexpensive measures, using the local features to set a specific refurbishment program that has a low impact on the built environment itself, but significant effects on the social milieu of specific neighborhoods.

It is internationally recognized that the environment surrounding us significantly affects our belonging sense to a place or a community, and, therefore, our social, mental and physical health (see Lady Allen of Hurtwood [2]). And since children are just learning about the world, their living environment will deeply influence almost all the main facts in their lives (see Kytta et al. [3]). This topic, initially studied in the 1960s and 1970s (see, e.g. Gump [4], Lynch [5], Ward [6], and so on), has been recently revaluated (see, e.g. Aiken et al. [7], Augenstein et al. [8], Zanato et al. [9], and so on), becoming more and more important in the planning field, as our cities have grown further and further, creating wide environments, in which children have significant problems in relating to the external factors, mainly in developing countries (see, e.g. Ramezani et al. [10], So et al. [11], and so on), where cities can reach higher levels of gentrifications (see van den Berg [12]) and age classification in their different communities and neighborhoods.

The main features of a child-friendly city (CFC) have been articulated several times in many different ways, also by the most important organizations in the worlds (e.g. the 
$\mathrm{UN}$ ), and there are different checklists reported by the most significant exponents of the relevant debate and in the concerning literature (see also Broberg et al. [1]), but the research proposed in this article has also been focused on the synthesis of a list that could sum up the main factors that a urban system should have to be considered as a completely child-friendly environment. Actually, Driskell lists the CFCs characteristics in his renowned book ([13]), wrote after the culmination of a twenty-six-year project sponsored by UNESCO and conducted in the social and human sciences sector. In this very comprehensive work, embracing the previous studies knowledge and the referred project experience, child-friendly city characteristics are indicated as follows:

1. Good access for all children to affordable, quality basic health services, to clean water, to adequate sanitation and solid waste removal systems;

2. Committed local authorities, as they should ensure that policies, resources allocations and governance actions are made in the best interests of children and their constituencies;

3. Safe environments and conditions, that nurture the development of children of all ages with opportunities for recreation, learning, social interaction, psychological development and cultural expression;

4. A sustainable future under equitable social and economic conditions and protection from the effects of environmental hazards and natural disasters;

5. Participation policies, as children have the right to contribute in making decisions that will affect their lives in the future and they should be offered opportunities to express their opinions;

6. Special attention to disadvantaged children, such as those who are living or working on the streets, or are sexually exploited, or are living with disabilities or without adequate family support;

7. Non-discrimination policies based on gender, ethnic background or social and economic status.

\section{CFCs: Theories and Best Practices}

In North America and Europe a lively literature emerged from the 1960s in the attempt to give more explicit attention to the links between urban development and children welfare: see e.g. Ward [6], that distilled this complaint with industrial modernism and proposed a urban concept that was more conscious of children different needs, including their abiding preference for secure home worlds over broad cityscapes. The growing critical focus on children among urban commentators was stimulated by the establishment of a ten-year program in 1968, called 'Growing Up in Cities', originated in the 1970s under the direction of Kevin Lynch and coordinated by the United Nations Educational, Scientific and Cultural Organization (UNESCO). It was an international program which consisted of interdisciplinary teams of municipal officials, urban professionals, and child advocates around the world, working with young people themselves to create communities that are better places in which kids can grow up - and, therefore, better places for us all. But a great part of this discussion focused on specific matters, such as how some issues of the child psychology were influenced by environmental conditions (e.g. Gump [4]) or narrow concerns with the physical design of child play areas (e.g. Lady Allen of Hurtwood [2]). Overall, the ambition of these projects and works was not really to re-centre children in the society, but to urge greater institutional awareness of their unique and sensitive qualities (e.g. Lynch [5]). Children were still at the core of the modernization project, but institutions were behaving apathetic, providing thoughtlessly solutions for their assumed, not considered needs.

While many of the project goals remain the same as they were in the 1970s, there has been an important shift towards a more participatory and action-oriented approach. This is due in part to the policies that now exist at the international level and to the growing support for participatory, democratic approaches to the urban development. It is also due to more widespread and severe urban problems, that are impacting children lives in increasingly negative and visible ways, challenging us to do more than just understand what is happening. We need to take action. Most importantly, the strong participatory orientation of the contemporary 'Growing Up in Cities' project is due to the increasing demand among local communities to be heard and involved in the decisions that affect them.

As said before, in the recent years we have witnessed a renewed interest in the public and professional debate of children issues in English-speaking countries. Specifically, children physical health has emerged as an area of significant concern with the recognition that the levels of physical activity among urban children have been declining, mainly in the developed countries, such as the United States, the United Kingdom, Australia (see Whitzman et al. [14]), Finland (see Broberg et al. [1], Kytta et al. [3], Laaksoharju et al. [15]), and so on. Scholarly research and popular interest in children health has continued into the twenty-first century, particularly focusing on the incidence of childhood obesity and the associated decrease in children physical activity. Referring to the concern about childhood obesity, a growing range of studies has examined the links between children physical activity patterns and built environment forms. Other works have pointed out an alarming rising of mental health disorders among children in countries such as the US, the United Kingdom and Australia.

\subsection{The Main Spatial Features of CFCs}

In the light of the results of Driskell [13] studies, this article aims to highlight how the features of child-friendliness come into existence in built environments and what kind of spaces are able to answer to those criteria. Actually, child-friendliness from a spatial perspective could 
be summarized in a three parts list, namely made by integration, accessibility, and exciting outside environment.

Integration in CFCs means taking action and getting involved. Since the 70s, scholars thought and discussed about the issue. Kevin Lynch [5] said that: «Children should be living in places that have a clear social and spatial identity, places that can understand and take pride in. They should have a role to play in community maintenance and community celebration, particular functions to perform, particular places for which they are at least in part responsible». This means that children should be able to take part in the real urban life. Otherwise, the simulated worlds, prepared specifically for them, offer pretty poor training grounds for their future life. In addition to what Lynch stated, Colin Ward [6] underlined the importance of the interaction of kids with their community. He declared that children should take action and responsibility in the community life.

As it was discussed also by Orietta Zanato [9] and her group in 2011 at 'The City Crisis UN World Conference', the cities suffer today from either the existence of 'hyper-specialized spaces' or the existence of 'abandoned everybody's spaces'. They are claiming that in the actual context, consisting of highly 'hyper-specialized spaces', 'spaces of everybody' are no longer 'everybody's spaces'. They are becoming the spaces to pass across, but not the places to establish relationships with other community members. Especially, the community members in 'weaker' positions (especially, children, elderly classes, women, foreigners, disabled, etc.) are more afraid of using those spaces. As a result, they reject to socialize in those spaces, and become more isolated and frightened (see Zanato [9]).

To sum up, children need, first of all, to recognize and understand where they live. There should be some 'city experiences' in their lives. They should use the city and also take responsibility in the community. But also, the city enterprises and facilities should be rethought and redesigned in a way that give children the opportunity to get involved.

Secondly, it is the accessibility, which provides friendly urban environments for kids. Creating isolated sandboxes in some points in a city is not the proper way to think to the presence of children in the urban area. The lack of consideration about children in the design of open spaces, the uncontrolled busy traffic, the neglected dangerous places are the main boundaries to the freedom in moving of young citizens. Another important thing to take into consideration is the perception of space that children have. It is sometimes the perception rather than the reality, which sets boundaries for children. So, while working on micro-environments, the people in charge should be aware of the children perception and then design the urban spaces accordingly. In an accessible city, children should be able to reach different parts and attraction points, without any guidance of their parents or teachers.

It is obvious that the streets are thought more and more just for cars and the actors, who play a role in the traffic, are perceived as simply the vehicle drivers, but not the pedestrians or cyclists anymore. This kind of point of view dramatically affects the new constructions and policies against pedestrians and cyclists, especially, if they are children. While in the education system the importance of independency is underlined, outside of school kids are facing an approach that is just at the opposite. The ease of moving and accessing places is the most important factor in a city that is thought for children, for their mental, social, psychological and also physical development.

Thirdly, it is the exciting outside environment, which encourage and invite the small members of the community to 'mess around' after school or on holidays. The features that make a city friendly for its children are its inviting local and/or dead-end streets, its courtyards, its apartment staircases, its wide pedestrian ways, and so on. The outside environment is getting more and more boring for children in most cases. The security precautions set in the places, where they should live and that are especially designed for children, make these environments unattractive and, also, children cannot play properly in the non-programmed spaces, because of parental fears. As a result, children are giving up using the city for their leisure time activities day by day. In this circumstance, planning and designing the urban and also natural environment as an attractive mean to play and 'mess around' should become the primary concern of the people in charge. A balance should be found. While children can face with challenge in designed playscapes, they also need to find enough audacity to use the wastelands and other 'left-over' spaces as recreational areas.

\subsection{Planning for and with Children}

Achieving a child friendly environment is one of the most important tasks for people who are working in the caring, teaching, designing and policy-making fields dedicated to children. All the efforts should be focused on making the children aware of their importance, building their sense of identity, to live in a positive way the unique experience of childhood and to get prepared for the future. All these tasks need a lot of attention and real willingness to be helpful. Unfortunately, while everybody in these sectors seem to be primarily concerned by children, the failure of their practices shows us that there are other stories hidden behind the ideal picture of child friendliness.

Children are not suitable for short-term investments. They are not valuable enough to work for. They don't vote, they don't pay taxes, and also their opinions cannot be so reliable. In the end, statistics are becoming more important than children feelings and values. Or even, there are always much more important problems, so that none of the authorities is paying attention to those small citizens problems. Also they are not reliable enough to work with. They don't understand properly and they don't have a reliable capability in problem solving. Also, adults know what children want better than they do. It is obvious that, this way of thinking brings us to a world where children watch TV and play on computer more and more, if they have such an opportunity. So, exactly in a world where there is even no real effort in many cases to 
work for children, the importance of getting kids included in the decision making process is becoming imperative, strategic and vital.

Inclusion of children in planning provides advantages for all the stakeholders. In his book, Driskell [13] states the benefits of children inclusion, articulated for kids, for other members of the community, and for planners and decision makers. First of all, it provides the means for children to be involved in the real community life, to learn about democracy, to develop their identity in a place, and to strengthen self-esteem and confidence. Secondly, for the other members of the community, it gives the opportunity to interact with young people and invest time and energy for the future of their community. Finally, it helps the planners and policy-makers to more fully understand the needs and issues of the communities and to create urban environments that are more child-friendly and humane [13].

How to include the children in design and planning becomes here another essential question to be answered. Children participation in design and planning has a more-than-30-year history now and, during this time, different meanings were assigned to it. Different approaches based on different theories have been experienced. This part of the article performs a brief analysis of the different realms of children participation developed in the recent past, which is divided into seven categories, discussed by Mark Francis and Ray Lorenzo [16]. The issue of participation firstly started with the perception of 'children as planners' or as 'futurists'. Planning is done by children. Children define and make their own future, often without adults involvement. Much of the 'rights' movement grew out of this approach. After this realm, the advocacy realm arose. In this approach, 'planners' were 'for children'. Planning is done for children with needs advocated by adult planners. After that, the 'needs realm' occurred. Accordingly to this approach, it was the 'social science', which is 'for children'. Its theory came from the research-based approach that addresses children needs. After the 'needs realm', the 'learning realm' appeared. 'Children' perceived 'as learners'. Its theory was based on participation of children through environmental education and learning. Later, there was the 'rights realm', which affected the current practices of this time. In this realm, the approach is based on the perception of 'children as citizens'. Its theory stated that children have rights and those rights need to be protected. Then, the 'institutionalization realm' appeared. Its approach was based on the perception of 'children as adults', and its theory claimed that planning is done by children, but within institutional boundaries set by adults, authorities, and clients. And lastly, the 'proactive realm' has emerged. Its approach is based on the motto of 'participation with vision'. Planning is done with children. Its theory combines research, participation and action to engage children and adults in planning and design. Children were active participants in the process, but designers and planners play an important role.

\section{The Tarlabasi Case Study}

Tarlabasi is a very problematic inner city slum today, which is always experiencing a constant immigration process. During its history, the area hosted different immigrant groups in different periods. And also today, there is a mixture of immigrants coming from different parts of Turkey and even from different countries. Some of them are new-comers, while some of them are the second or the third generations in the family, that originally immigrated to the area. In order to provide a better understanding about the inhabitants of Tarlabasi, it was considered necessary to share the knowledge gained through a comprehensive field research conducted by the Tarlabasi Community Center in around 67 different streets of the district, which gives a significant insights about the socio-economic conditions of Tarlabasi inhabitants and a synopsis about the problems of the area (high crime rate, high unemployment rate, discrimination, poverty, illegality, difficulty to adaptation to urban life, marginality, and so on). Despite all the problems that children and also adults face in the district, the hidden values of Tarlabasi, and the very unique opportunities that it provides to its children, were the reason why the neighborhood has been chosen for this to study. According to the statistics, Tarlabasi has one of the highest crime rate in the city. However, except for the night time, its streets are full of people, knowing and talking the one to each other. It is because the people in Tarlabasi don't have so much space in their houses. So, some activities take place in the streets, creating strong relationships between neighbors, which make the community members (including also the 'weaker' ones) feel confident to live without any limitation caused by fear. Consequently, someone, that thinks that the urban poor children are the most unlucky group among urban kids, might be wrong. The studies conducted by very important scholars, like Kevin Lynch [5] and Jane Jacobs [17], showed that, sometimes it is the poorest part of the city, that provides the friendliest and welcoming environments for its inhabitants. Also, the results of the researches conducted to understand children perception indicate that a pathetic space for an adult eye, could be a bliss for children. The spaces of children don't have to be glorious or luxurious. Giving chances for integration, confronting children to feel safe, providing green spaces, and encouraging them to move and activate on their own, are the main features of a child-friendly city. These are the features, which affect their perception of space. If the children get involved in the community life, and move safely on their own and play, that place becomes their reference, regardless of its luxury, as it is happening also in Tarlabasi, much more than in many other neighborhoods in Istanbul.

\subsection{Children in Tarlabasi}

There are many young inhabitants, who try to grow up in these very problematic conditions. After learning about the problems in the area, the research team tried to focus on the 
ways to understand what it is like to be a child in this inner city slum. To be able to answer to this question, the research team both made academic and field research. As academic research, comprehensive and specialistic materials, produced by Tarlabasi children, have been read. With the help of the Tarlabasi community center, the children are publishing a monthly magazine, whose content totally belongs to them. They also add the photographs that they took, make interviews with the local tradesman, with other kids, or with their teachers, so that they show and express themselves. After checking dozens of magazines, the research team noticed the attention which is given to be polite and clean. The children were repeating the importance and virtue of being polite, even if the person, who was talking to them, was not, or the importance and virtue of being clean, even if the people around them are not. These children are surrounded by wrong prototypes or by children who have been raised by those wrong examples. So, even very simple things, which are thought automatically by parents, are becoming something that they have to learn on their own. So, these magazines, for instance, are becoming the means to teach them these basic things the one to each other. In the magazines, there was also a special focus on the lack of appropriate spaces to play and move, and the lack of integration with others. The children are not directly expressing these problems in this way, but the answers to the questions, such as 'what do you like to do the most', or 'what do you miss to do the most' were mainly 'to see some landmarks in Istanbul' or 'to go back to the village and ride a horse or play with the other kids'.

During interviews with the community center director, she had also mentioned about this children common wish of going back to their villages. In the research team opinion, what they cannot find in Tarlabasi, and the main reason for this sense of missing the village life, is their social, psychological, and physical isolation from the urban environment in which they live. They neither have any open space properly designed for their needs in Tarlabasi, nor have enough encouragements or physical connection to reach to the well developed zones around it. In the magazine, one answer to the question of 'your primary wish' was to fly and to see Istanbul. For that kid, to see the city, in which she lives, could be possible only by flying, that can be also a nice childhood dream, but these children in Tarlabasi are really suffering from isolation. It is lastly to be added a wish of a child that gave as an answer to an interview question. His wish was to have 'another special school' designed only for disabled children in their neighborhood. He said that he feels sorry for the children who don't go to school, because of their disabilities. A child mind can think that the school for disabled children should be something very special, but as adults we know that with some simple adjustments according to the rules of universal design, schools can become friendly almost for any kid. In addition to the magazines, the research team considered it worthy to touch on the photographs that were taken by children of Tarlabasi. In the summer of 2007, the community center distributed some disposable cameras to children and asked them to take pictures for a program called "The Life in Tarlabasi". There are photographs showing the small interiors of their houses, children at play and at school, adults while working. As it is seen from the photographs, and also as the research team saw with during the field research, they have an active community life. Children play in the streets and at home, both kids and adults are sitting in front of the door of their houses. There are also some photographs representing streets and focused on the beauty of their old buildings. Even if everything is old and dirty, it is seen that, there are habits and lifestyles adapted to Tarlabasi conditions. And playing in the middle of the street in front of the house or sitting in front of the exterior door in the 21 st Century is not something that could be missed.

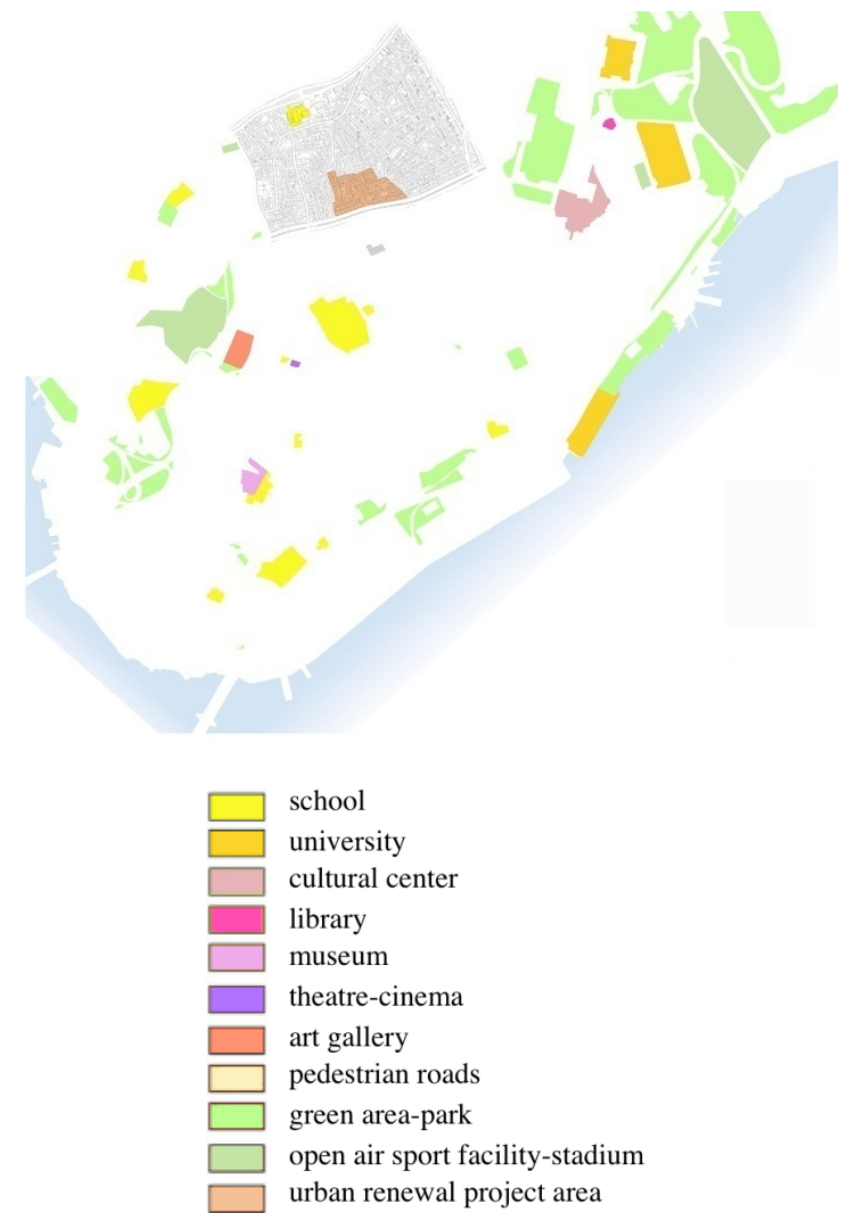

Figure 1. Map of Tarlabasi and the facilities in its near surrounding

Tarlabasi offers some unique spaces with its dead-end streets and with the niches of its houses. For sure, only streets and niches cannot be enough for a neighborhood and kids strongly need some open spaces, but that much complains cannot be only the result of the poor physical conditions and lack of facilities. As far as seen by now, it is the adults' perceptions and attitudes, which affect the children point of view. It is also adults' wrong and careless behaviors, which affect children the most. Until recent years, some unqualified and uneducated parents were using their small children to work and earn money. This was a never ending vicious cycle. 
The parents, who worked in their childhood instead of going to school, asked their children to work and earn money again, instead of going to school. It was also because they couldn't find proper jobs without a proper education. Tarlabasi used to have the neighborhood which has one of the highest street children population in Istanbul until recent years. However, this situation has changed now. the importance and positive impact of the careful efforts spent by local authorities and also the community center employees is to be underlined. Today, both of them, and also the teachers working in the public neighborhood schools, are working very hard to change the life of the young inhabitants of Tarlabasi. The new policies, which are strictly protecting the children rights, the youth centers, the Tarlabasi Community Center helped solving many problems that actual adults faced, when they were children in Tarlabasi. Now, every child is going to school, instead of working. The authorities are trying to help families, even financially. And if something still doesn't work, they punish families, or even pull out children from them. Tarlabasi is a place, where many good and bad things happen at the same time. The same authorities are also trying to send these families to the outskirts of Istanbul, where there are law quality building blocks without any identity.

\subsection{Problems and Potentials in the Area}

Based on the authors' observations, the problems of the district, which obstacle Tarlabasi to be a child-friendly neighborhood, have been analyzed and discussed. As the first problem, it is seen the boulevards with busy traffic surrounding the neighborhood, which is affecting very negatively the mobilization of the young inhabitants of Tarlabasi on their own. As the second problem, it is observed the high crime rate in the night time, which is caused by the broken lighting system and the absence of the surveillant eyes of the community at nights. As the third problem, the over-neglected facades and street pavements are considered, which strengthen the inner city slum image of the neighborhood. And as a last problem, the careless execution of the urban renewal project in the area is noticed. Many of the inhabitants of the urban renewal area were forced to leave their houses without their desire. They were sent to the outskirts of Istanbul, which caused the parents not to effort the travel allowance to work and lose their jobs consequently. But, as already underlined, Tarlabasi is also a neighborhood of Istanbul with full of potentials, despite all of its problems. First of all, it is located next to the most touristic and well-developed area of Istanbul, full of cultural, educational, and sports facilities. Secondly, it is a neighborhood, where there is 19th Century Istanbul houses and a well developed infrastructure, although they have been significantly neglected for dozens of years. And, lastly, there are unused courtyards, terraces, and front door niches of apartment blocks, which have the potential to convert Tarlabasi into the most adventureful and exciting neighborhood of Istanbul for its small citizens.

\section{Problems, Potentials, Proposals: 3P}

Choosing Tarlabasi among many problematic districts of Istanbul to analyze and propose a project comes from the idea that giving chances for integration, confronting children to feel safe, providing green spaces, and encouraging them to move on their own, are the main features of a child-friendly city. It was the foresight about the hidden values of Tarlabasi, which made the research team be willing to make a research about this district. After talking with the Tarlabasi Community Center director, Ceren Suntekin, explaining her the research aim, it was her first sentence, which showed that it wasn't a mistake. She said, she was waiting for someone who sees the very unique opportunities that Tarlabasi provides to its children. She was definitely aware of all the problems that the children and also the adults face in the district. However, it was Tarlabasi children who walk to their school on their own, and who walk along its streets and play after school, while the children in almost all the other neighborhoods of Istanbul are losing their very precious hours in traffic jams and got stuck in their houses, schools, or shopping malls.

Walking one day in a very narrow street, there was a young women standing in front of her house. This was a very usual scene, because the people in Tarlabasi are using the space in front of their houses very frequently. They don't have so much space in their houses, so some activities take place in the streets. Anyway, so much attention hasn't been paid. And then, the researchers both see old women in the end of the street: the Tarlabasi Community Center director, Ceren Suntekin, suddenly started to shout at that old woman about how worried they were, because they didn't hear anything from her. After a while, it was understood that they were neighbors and the old women went to the hospital early in the morning without telling anyone. It was just one example, but there is no strong relationship between neighbors in many other neighborhoods in Istanbul. So, it was understood that it is the special network of neighborhood relationships there, which makes the community members, including also the 'weaker' ones, like the old woman, feeling confident to live without any limitation caused by fear. Well, the real situation was not like we thought then. While millions of people in Istanbul couldn't leave their children or old parents without their surveillance, in the day time, in Tarlabasi, children that walk home on their own from school are asking people to take them pictures, or old people go to the hospital without anybody help. Regardless from anything else, these values are worthy to be explored and protected.

Therefore, the proposed project (called "3P") has been divided into three orders of elements that have helped the researchers to set a panel of simple actions to be implemented, in order to solve the main local problems and benefit of the main potentials of the Tarlabasi community. First of all, the further research was set after identifying the main problems of the local community:

1. Inner-City Slum Isolated with Boulevards, 
2. Busy Traffic and High Speed in Surrounding Boulevards,

3. Lighting of the Streets: Out of Order,

4. Abandoned Ground and First Floors because of Unsafety,

5. Absence of Surveillant Eyes of the Community During the Night,

6. The High Crime Rate,

7. Absence of Public Open Space,

8. Over-neglected Facades and Street Pavements,

9. Careless Execution of the Tarlabasi Urban Renewal Project.

The Tarlabasi community is considered as highly problematic, but after a Swot analysis, the research highlighted a significant number of potentials to be used to implement a simple, but radical renewal of the built and social networks:

1. The Well-developed Touristic Area with Full of Facilities next to Tarlabasi,

2. The Cultural and Educational Buildings, Green Areas, and Sport Facilities in and around Tarlabasi,

3. Dead-end Streets and Pedestrian Roads in and around Tarlabasi,

4. Chance of Solving Security Problems with Small and Achievable Precautions,

5. The Potential of Existing Infrastructure,

6. The Potential of Existing 19th Century Facades,

7. Abandoned Ground and First Floors,

8. Niches in the Entrance of the Houses,

9. Open Spaces used as Car Parking Areas,

10. The Unused Courtyards of the Building Blocks in Tarlabasi,

11. The Terraces of the Houses in Tarlabasi,

12. The New Atmosphere Gained through Urban Renewal Project.

In the light of the given problems and potentials, a project made of a list of simple, interchangeable, modular and inexpensive actions has been realized, in order to minimize the effects of the downplays of the local situation and to use the highlighted potentials to enforce the effect of the provided actions in the community:

1. Fixing the Lighting System,

2. Reconditioning Dead-end Streets and Pedestrian Roads,

3. Implementing Proper Designs for the Unused Courtyards,

4. Implementing Proper Designs for Public Squares and Empty Plots,

5. Reconditioning the Terraces,

6. Reconditioning the Niches in the Entrances of the Houses,

7. Reconditioning Vehicle Roads and Sidewalks,

8. Converting the Boulevard into an Urban Corridor and a Mixed Use Zone,

9. Renovating the Abandoned Floors,

10. Renovating the Front Facade of Protected Buildings and Consolidating the Structure.

\section{Cost Estimation of the Solutions}

As a neighborhood, which seems very problematic and disadvantageous, Tarlabasi has very unique potentials to be converted easily to a good place to live in or grow up. Referring to the analysis of problems and potentials in the area, some simple but effective solutions have been proposed and their cost estimation is made. The solutions are some design, reconditioning, and renovation works, whose costs change according to their scale and type. While making the cost estimations of these projects, it is decided to start from the cheapest work and continue with the more expensive ones regardless from their impact. In the light of these concerns, the first project, whose cost estimation is made, will be 'fixing the lighting system', the second project will be 'reconditioning dead-end streets and pedestrian roads', third project will be 'implementing proper designs for the unused courtyards', fourth will be 'implementing proper designs for public squares and empty plots', fifth will be 'reconditioning the terraces', sixth will be 'reconditioning the niches in the entrance of the houses', seventh will be 'reconditioning vehicle roads and sidewalks', and the eighth will be 'renovating the front facade of protected buildings and consolidating the structure'.

Cost estimation of fixing the lighting system is the cheapest solution to the security problem in the neighborhood, because there is already a well-developed infrastructure for lighting. The only thing that should be done is buying new bulbs for the broken ones. According to my rough estimation, the length of the primary and secondary streets is $10.000 \mathrm{~m}$, and this length needs around 500 bulbs from $2.5 \$$ each. So, it costs around $1.250 \$$ in total.

Cost estimation of reconditioning dead-end streets and pedestrian roads is second economic solution for Tarlabasi. Because of the slope of the streets, there are many stairs along them, which provides the connection between level differences. And this resulted with the creation of some dead-end streets and pedestrian roads. Again these streets are suffering from negligence, and give a depressive impression to their users. The vehicle-free-streets or the streets, where the speed of the vehicles are not so high, are the places which provide unique opportunities for children to play and to gather. So, even if Tarlabaşı doesn't have enough urban spaces, these streets could be a perfect chance for eliminating this deficiency. Implementing concrete surfaces for these streets could be also a solution and it could be also much cheaper, because the price determined for $1 \mathrm{sm}$ of a 20 $\mathrm{cm}$-thick concrete ground is $20 \$$. However, because the quantity of these streets is not so much, and also because they provide excellent outdoor environments for children, the research team will make the cost estimation for the implementation of melted rubber for these streets. When the melted rubber ground implemented from $40 \$ / \mathrm{sm}$, the total cost of this implementation becomes around $48.000 \$$.

Cost estimation of implementing proper designs for the unused courtyards becomes the third most economic solution. In Tarlabaşı, every building has a door in its ground floor 
opening to a courtyard, because the area consists of islands having a courtyard in the middle. And these courtyards are suffering from negligence, unless they are used as parking lots. So, another potential of the area is designing at least a small part of each courtyard for the use of children or buildings' occupants. Also, most of the courtyards already have a door opening to a street, which provides an opportunity for these courtyards to become a public space. The number of courtyards in Tarlabaşı is approximately 60 . Obviously, the area of the courtyards is not equal. While some of them are very small, some of them are quite large. That large ones are mainly used as parking lots. However, to make a raw cost estimation, it is reasonable to assume approximately a $12 \mathrm{sm}$ area for each courtyard to be converted into a playground, or an outdoor gathering place. When the playgrounds are constructed in the places of these courtyards, the total cost becomes roughly $106.000 \$$.

The project of implementing proper designs for public squares and empty plots comes as the forth among the other projects in terms of the costs. There are very few public squares in Tarlabaşı, and they are used either for car parking or they are the plots of demolished buildings. This proposal is about implementing proper designs for these urban spaces. Making this kind of a project does not cost too much, but it changes a lot in the perception of inhabitants. The Ministry of Environment and Urban Planning published the costs per unit area of different building types and urban spaces. According to their publication; playground, sports field or small neighborhood park constructions for Tarlabasi neighborhood cost roughly $150.000 \$$.

The fifth project, in which the projects are listed in order to their costs from the cheapest to the most expensive, is the reconditioning of the terraces. This reconditioning work basically means painting the exterior walls and repairing the flooring of the terraces and supplying some equipment for cultivating some plants or some furniture for terrace. The total project costs around $160.000 \$$.

The sixth project in the list is reconditioning the niches in the entrances of the houses. This reconditioning work basically means painting the walls of the niche and polishes the exterior doors and the steps in front of the doors. It costs in total around $485.000 \$$.

The seventh project, which will have a dramatic change in the district, is reconditioning vehicle roads and sidewalks. In Tarlabaş1, the vehicle roads and the narrow sidewalks are in really very bad conditions. However, as it is seen from the old pictures of the neighborhood, the roads had cobblestoned pavements once upon a time. So, to change the poor and neglected impression of Tarlabaşı, projecting cobble- stoned pavements to its streets and reconditioning its sidewalks could be one of the best solutions. This change costs around $1.060 .000 \$$.

The last project is renovating the front facade of protected buildings and consolidating the structure. This is the most expensive project proposed. However, Tarlabasi has the inheritance of a few of the last remained 19th century buildings of Istanbul. Most of the buildings are protected by laws, because they are historical heritage. So, a renovation project there is very reasonable. This is also what the government does now in the islands of $360,361,362,363$, $385,386,387,593$, and 594. The project is called Tarlabasi Urban Renewal Project. But it is executed as a gentrification project rather than an urban renewal project. In Tarlabasi, in these islands, there will be totally a new physical and social environment soon. Fancy apartments, ateliers, and shops will be ready in a few years for their new occupants. Except the authorities and the new investors, nobody is sure about the accuracy of this solution found to solve the problems of Tarlabaşı. So, it is strongly necessary to underline here the purposes and intentions of the last proposed project in this artcile, which aims to change the inner city slum image of Tarlabasi, not its current inhabitants, or craftsmen, or tradesmen. In the light of all these concerns, the project is thought as renovating the front facade of protected buildings and consolidating the structure, and it costs roughly $97.000 .000 \$$.

\section{Conclusions}

In a world, where parents spend more and more money for their children and determine the neighborhood, which they live in, according to the quality of schools, it is tried to be discussed the spatial child-friendliness of a place and the criterions are evaluated over the Tarlabasi case study. While the criterions are summarized through the overview of existing literature, it is especially avoided to come up with general ideas and judgments originated from the findings of Tarlabasi case study. In the light of these concerns, it is seen that Tarlabasi is a more child-friendly neighborhood than an average one in Istanbul, although its reputation is very bad. While children in Istanbul mostly go to their schools by motor vehicles and spend their leisure time in front of computers, the children of Tarlabasi go to their schools on their own by walking and they play and mass around after school in front of their houses. With the help of community center and municipality, they get space and professional support to study after school and do their homeworks, although they don't have these at their houses. Whereas the problems arising from poverty and lack of education can be minimized by authorities, the obstacles for children to mobilize out of their neighborhood in the city cannot have been still overcome. Tarlabasi children don't use and take advantage of the various facilities in their near surrounding. Both they and their parents are not even aware of the existence of these facilities. The drawbacks for this are the adults' fear and espousal of exclusion as much as the physical disconnection. So, it is observed that the society prejudices cause more serious problems than poverty. With the amount of money and effort spent for the urban renewal project to dispel the problem of fragile Tarlabasi inhabitants presence in the middle of the city, the negative physical conditions in the neighborhood, and the biases and the negative opinions of the society could be overwhelmed. 
Disposal of poor, weak, and ugly is not going to solve any of the problems. On the contrary, it will lead the extinction of rare and uncommon lifestyles of the city.

\section{REFERENCES}

[1] A. Broberg, M. Kytta, N. Fagerholm. Child-friendly urban structures: Bullerby revisited, Journal of Environmental Psychology, Elsevier, Jena (Germany), 2013.

[2] Lady Allen of Hurtwood. Planning for Play, Thames \& Hudson, London (UK), 1968.

[3] M. Kytta, A. Broberg, M. Kahila. Urban environment and children's active lifestyle: softGIS revealing children's behavioral patterns and meaningful places, American journal of health promotion, Allen Press Publishing Services, Lawrence (KS, USA), 2012.

[4] P. V. Gump. Ecological Psychology and Children, University of Chicago Press, Chicago (IL, USA), 1975.

[5] K. Lynch. Growing Up in Cities, MIT Press, Boston (MA, USA), 1977.

[6] C. Ward. The Children in the City, Architectural Press, London (UK), 1979.

[7] K. Aiken, C. Bowns, M. Francis. Healing Environments: A Collection of Case Studies, Center for Design Research, University of California, Davis (CA, USA), 1994.

[8] R. Augenstein, B. Gonzalez, M. Pena. Geopark: A new playground using resources from the offshore oil industry, available on http://www.hha.no/projects/geopark/ (retrieved on November 20th, 2011), 2008.

[9] O. Zanato, F. Bussi, A. Cesaro, D. Luise, E. Maggiolo, C.
Mauro. Education for the City, the City for Education. In C. Beguinot (Ed.). The City Crisis, The Priority of the XXI Century, Giannini, Naples (Italy), 2011.

[10] S. Ramezani, I. Said. Children's nomination of friendly places in an urban neighbourhood in Shiraz, Iran, Childrens Geographies, Routledge Journals, Taylor \& Francis LTD, Abingdon (UK), 2013.

[11] K.S. So, S. Shin. The Design and Development of a Child-Friendly Pedestrian Environment in School Zones, Architecture and Urban Development, Advanced Materials Research, Trans Tech Publications LTD, Zurich (Switzerland), 2012.

[12] M. van den Berg. City Children and Genderfied Neighbourhoods: The New Generation as Urban Regeneration Strategy, International Journal of Urban And Regional Research, Wiley-Blackwell, Hoboken (NJ, USA), 2013.

[13] D. Driskell. Creating Better Cities with Children and Youth. A manual for participation, Unesco Publishing - Earthscan Publications, 2002.

[14] C. Whitzman, D. Mizrachi. Creating Child-Friendly High-Rise Environments: Beyond Wastelands and Glasshouses, Urban Policy and Research, Routledge Journals, Taylor \& Francis LTD, Abingdon (UK), 2012.

[15] T. Laaksoharju, E. Rappe, T. Kaivola. Garden affordances for social learning, play, and for building nature-child relationship, Urban Forestry \& Urban Greening, Elsevier, Jena (Germany), 2012.

[16] M. Francis, R. Lorenzo. Seven realms of children's participation, Journal of Environment Psychology, $\mathrm{n}$. 22/2002, 157-169.

[17] J. Jacobs. The Death and Life of Great American Cities, Random House, New York, 1961. 